\title{
Alternative Liquid Assisted-Sintering of AL/CU Composites Using Selective Powders of AS-Cast Al- ZN Alloy
}

Eder Lopes Ortiz

University of Campinas (UNICAMP)

Wislei Riuper Osório

University of Campinas (UNICAMP)

Ausdinir Danilo Bortolozo

University of Campinas (UNICAMP)

Giovana da Silva Padilha ( $\nabla$ giovanap@unicamp.br)

UNICAMP https://orcid.org/0000-0001-7425-8934

\section{Research Article}

Keywords: intermetallic phase, Al6Cu5Zn alloy, powder metallurgy, mechanical properties

Posted Date: January 5th, 2022

DOI: https://doi.org/10.21203/rs.3.rs-1189614/v1

License: (a) (i) This work is licensed under a Creative Commons Attribution 4.0 International License.

Read Full License 


\section{Abstract}

Al and its alloys constitute one of the most versatile, economical and attractive materials for a wide range of applications. The 7xxx and 2xxx series alloys are those of achieving the highest mechanical strength among aluminum alloys. In this investigation, using powder metallurgy provides the microstructural and mechanical properties characterizations of non-commercial Al6Cu5Zn alloy by using powder metallurgy. Initial powder sizes are determined and the best condition is obtained for the distribution comprised between $75-106 \mu \mathrm{m}$. The samples are sintered at $585^{\circ} \mathrm{C}, 600^{\circ} \mathrm{C}$ and $615^{\circ} \mathrm{C}$ during $0.5,1.5 \mathrm{~h}$ and $3 \mathrm{~h}$. It is found that mechanical behavior similar to as-cast Al-Cu based alloys is attained ( $125 \mathrm{MPa}$ ) when the samples at $615^{\circ} \mathrm{C}$ during $3 \mathrm{~h}$ are sintered. Considering the reduction of energy consumption and metal fumes commonly produced in foundry, Al-Zn powder can be used with Al and Cu elemental powders to constitute an Al6Cu5Zn alloy.

\section{Introduction}

Both 7xxx and 2xxx series alloys are heat treatable alloys and high mechanical strengths can be reached. Due to this reason, these alloys are commonly used into automotive and the aircraft industries [1]. This encourages the research and development of new materials and manufacturing methods. Aluminum alloys are attractive for use in distinct engine parts constituting lighter structures and more effective compared to the materials previously employed. Besides, the vehicles save energy and consequently pollution is reduced with improving the performance [1, 2].

Although Al alloys exhibit a high strength-to-weight ratio, improvements of the mechanical properties with reinforcements are provided and new blends of Al alloys are constituted. The mechanical properties and application the both automotive and aircraft parts of Al-alloys are dependent of added elements $[1,3]$. Metallic and non-metallic elements such as $\mathrm{Fe}, \mathrm{Cu}, \mathrm{Pb}, \mathrm{In}, \mathrm{Zn}, \mathrm{Ni}, \mathrm{Mg}, \mathrm{Si}, \mathrm{Ti}, \mathrm{Sn}$, etc; are responsible to improve the mechanical properties when commercial alloys Al-based are investigated $[2,4-7]$. When $\mathrm{Zn}$ content is utilized, a liquid phase formation in an Al-Cu binary system is formed [8]. This enhances the liquid phase stage increasing the mechanical strength due to a surface free energy is provided. For this reason, the liquid phase flow is favored into the pores improving the adhesion of powders that can result in increased densification and, consequently, an improvement in mechanical property is attained $[3,5,9$ 10].

As aforementioned, the 7xxx series (Al-Zn) alloys, the Al-Cu (2xxx series) and Al-Mg-Si (6xxx and 5xxx) alloys are precipitation hardening aluminum alloys. These alloys have their hardness values increased by the control of the thermal treatment under specific conditions, i.e. solubilization and aging. The solvus temperatures (temperature above which the alloying elements enter unresolved) of the 7xxx series alloys are relatively lower than other aluminum alloys [11].

The zinc itself is highly soluble in aluminum and no appreciable influence on the microstructure is attained. However, a typical Al-Zn alloy commonly contains copper, as well as, chromium, manganese 
and zirconium contents. Besides, iron and silicon contents as impurities can also be detected. The precipitation hardening occurs in a sequence that starts with the formation of Guinier Preston zones (GP) from the supersaturated solid solution. Sequentially, the coherent metastable precipitates M' until reaching the phase of equilibrium $\mathrm{M}$ are constituted. These are occurred in the overaging stage, and a substantial decrease in hardness is observed [12].

Al-Cu system alloys, known as 2xxx (worked) and 2xx.x (cast) series alloys are the earliest developmental aluminum alloys. Their emergence dates back to the beginning of the XX century. Commonly, Al-Cu alloys have high mechanical strength after precipitation hardening heat treatment. However, despite this advantage, they have some disadvantages (e.g. corrosion resistance and limited castability) when compared with other aluminum alloys. The highest hardness values are obtained when copper contents ranging between 4 and $6 \%$ are used [12-13].

As previously mentioned, the Al-Cu alloys have high mechanical strength after precipitation hardening due to GP zones formation. These are characterized in disk-shapes formed by an arrangement of copper and aluminum atoms in the regions enriched in copper, promoting gain in hardness. This precipitate, which forms after a few hours, is coherent with the matrix and has platelet shapes. The continuation of the aging treatment leads to the formation of the equilibrium precipitate, corresponding chemically with the $\mathrm{Al}_{2} \mathrm{Cu}$ stoichiometry. This is called the thermodynamic equilibrium precipitate, since the continuation of aging does not change its characteristics, with the exception of the size of these particles, which tends to grow. The formation of this equilibrium precipitate also corresponds to the so-called overaging, and hardness is decreased [14].

Both binary groups of the Al-Zn and the Al-Cu alloys have limitations. The properties can substantially be improved by combining these elements in a blend Al-Cu-Zn that are basically 7xxx type alloy. Al-Cu liquid phase occurs at $548{ }^{\circ} \mathrm{C}$, while the Al-Zn liquid phase at $380^{\circ} \mathrm{C}$. In this way, the appropriate amount of $\mathrm{Zn}$ liquid phase within the melting temperature of Al favors to the sintering conditions of $\mathrm{Al}[3,15]$. Based on these previous investigations, it seems that using an AlZn master alloy associated with elemental Al and Cu powders a liquid phase can be constituted and assisted-liquid sintering is provided [8].

The casting process has usually been adopted for the manufacture of aluminum alloy parts. In addition to this process, on a smaller scale, the centrifugal casting and shell molding are also used. The selection of the manufacturing route depends on several factors, and aspects of the component adopted. The component size, shape and complexity, the physical and mechanical properties of the applied alloy, minimum and maximum thickness of each section, are some technical and operational aspects [16]. The economical factors are batch size and the relative costs of machining and finishing. The powder metallurgy (PM) is an alternative route associated with a lower energy and material consumption than those conventionally manufactured by using the traditional routes [17]. PM offers an economical method to improve the mechanical properties of aluminum alloys. However, some parameters should be optimized in order to low manufacturing cost and properties be attained. The utilization of powders 
obtained from ingots of the Al-based alloys induces to economic and competitive manufacturing route $[5,18]$.

Based on aforementioned, the proposed aim of this investigation is focused on the evaluation of the effect of both the distinctive sintering times (i.e. $0.5 \mathrm{~h}, 1.5 \mathrm{~h}$ and $3 \mathrm{~h}$ ) and temperatures (at $585^{\circ} \mathrm{C}, 600^{\circ} \mathrm{C}$ and $615^{\circ} \mathrm{C}$ ) on the mechanical behavior. Additionally, the resulting microstructural arrays of the Al6Cu5Zn alloy samples using SEM, EDX, and XRD techniques are evaluated.

\section{Experimental Procedures}

Commercial Al ingot is used ( 0.11 wt.\% Fe, 0.06 wt.\% Zn, 0.02\% wt.\% Mn; 0.009 wt. Cu and other $<0.001$ wt.\%). Electrolytic $\mathrm{Cu}$ and $\mathrm{Zn}$ ingots (99.90 wt.\%) are also used in order to obtain powder particles to constitute the Al6Cu5Zn alloy. An Al20Zn master alloy is produced (by using Al and Zn powders) to be blended with other powders to constitute the Al6Cu5Zn alloy samples. This procedure was also applied in previous investigation [3]. Additionally, this procedure is also carried out since $\mathrm{Zn}$ has a relative low melting point and in certain sintering temperature and period, the amount of $\mathrm{Zn}$ can be considerably lost. For this purpose, $\mathrm{Al}$ and $\mathrm{Zn}$ were melted at $600^{\circ} \mathrm{C}$ for $15 \mathrm{~min}$ and the master alloy is produced. In order to constitute the $\mathrm{Al} 6 \mathrm{Cu} 5 \mathrm{Zn}$ alloy, the adequate portions of $\mathrm{Al}, \mathrm{Cu}$ and $\mathrm{Al} 20 \mathrm{Zn}$ powders are prepared using a milling. Powders with particle sizes of between 75 and $106 \mu \mathrm{m}$ are selected. The follow powder masses of $\mathrm{Al}$ and $\mathrm{Cu}$ and $\mathrm{Al} 20 \mathrm{Zn}$ are used: $1.035 \mathrm{~g}, 0.09 \mathrm{~g}$ and $0.375 \mathrm{~g}$, respectively. Sequentially, these powders are handily mixed inside a mortar and pestle for $\sim 5 \mathrm{~min}$. A loading compaction of 10 ton using a uniaxial hydraulic press is used. The powders mixed are displaced inside a tempered ASTM A6 steel die with area of $270 \mathrm{~mm}^{2}$ in order to proceed with compactions. From the room temperature, i.e. $\sim 27 \pm 2{ }^{\circ} \mathrm{C}$, until 585 ${ }^{\circ} \mathrm{C}, 600{ }^{\circ} \mathrm{C}$ and $615^{\circ} \mathrm{C}$ applying a heating rate of $10^{\circ} \mathrm{C} \cdot \mathrm{min}^{-1}$, the compacted green samples are sintered under pure nitrogen atmosphere. The sintering time of $0.5 \mathrm{~h}, 1.5 \mathrm{~h}$ and $3 \mathrm{~h}$ are adopted. When combining the sintering temperatures and times, nine distinct sintering conditions are evaluated. Subsequently of the sintering stage, the samples are water-quenched at $27 \pm 2{ }^{\circ} \mathrm{C}$. A schematic representation of the powders metallurgy stages and sample synthesis is shown in Fig. 1.

A scanning electron microscope (SEM Zeiss, LEO 440) coupled with the Energy-Dispersive X-ray Spectroscopy (EDX) is used to microstructural array characterization. A PANalytical diffractometer (X'Pert model) operated under $40 \mathrm{kV}$ and $30 \mathrm{~mA}$ with $\mathrm{Cu}$ Ka radiation and wavelength of $0.15406 \mathrm{~nm}$ is used in order to the constituted phased be analyzed/determined. The $2 \theta$ range of $20^{\circ}-90^{\circ}$ is used. The relative densities of the samples are obtained by Archimedes' principle. For this purpose, a specific gravity measurement kit (SMK-401) from Shimadzu AUW220 $\left(10^{-4} \mathrm{~g}\right)$ is utilized. In order to carry out the thermal analyses, the samples of about $40 \mathrm{mg}$ are cleaned with alcohol/acetone solution $(1: 1, \mathrm{v} / \mathrm{v})$. A universal electro-hydraulic servo machine using a speed-cross of about $25 \mathrm{~mm} \cdot \mathrm{min}^{-1}$ and a strain rate of approximately $2.10^{-4} \mathrm{~s}^{-1}$ are used. Tensile strength measurements are carried out using samples with gage size of $\sim 25 \mathrm{~mm}$ (as depicted in Fig. 1) and ASTM standard (E8M/04). The effects of natural aging during 210 days upon the microhardness values of the sintered samples are evaluated. The Vickers micro 
hardness measures (HV) (Buehler - Wilson VH1102) according to ASTM E92 are carried out. At least 20 measurements are obtained for each one of the sides of the samples examined. For this purpose, a $9.8 \mathrm{~N}$ and a dwell time of $10 \mathrm{~s}$ are considered. The size particles are measured by using ImageJ $\circledast$ software. To guarantee the reproducibility of the values examined, in all characterization techniques, triplicate experimentation is considered.

\section{Results And Discussion}

\subsection{Powder characterization}

It is known the mechanical properties of alloy are affected by initial size of powders that controls the sintering kinetic. The powder size has a direct impact on the surface area. The number of small pores is produced by small particles the entire part, as reported by Mostafaei et al. [19]. It is known that hard-toductile particles ratio affects the resulting densification, as reported by Hafizpour and Simchi [20]. It is also reported that there is an adequate size ratio depending of the nature of the two or three distinct powders utilized constituting the composite examined [20-23]. Based on these assertions, in this present investigation a "quasi" 1:1 size ratio is utilized. Thus, the three distinct powders (i.e. Al, Cu and Al20Zn) are considered. Also, this constitutes a limitation and restriction of the study. In order to evaluate the effects of particle sizes up on the experimental ultimate tensile strength (UTS) of the Al6Cu5Zn alloy samples, the starting powders are analyzed. Four distinctive mesh ranges are evaluated, i.e. between 325 and 200 mesh ( 45 to $75 \mu \mathrm{m}$ ), 325 and 140 mesh (45 to $106 \mu \mathrm{m}$ ), 200 and 140 mesh (75 to $106 \mu \mathrm{m}$ ), and between 140 and 100 mesh (106 to $150 \mu \mathrm{m}$ ). These mesh values (ASTM E11-17) are considering with 1:1 size ratios and the resulting UTS attained are: $86( \pm 11), 84( \pm 16), 117( \pm 5)$ and $68( \pm 10) \mathrm{MPa}$, respectively. It is also remarked that a sintering temperature at $600^{\circ} \mathrm{C}$ for $1.5 \mathrm{~h}$ is adopted. Based on these experimental results, the 1:1 size ratio with mesh ranging between 200 and 140 is adopted.

Typical SEM micrographs of starting powders of Al, Cu and Al20Zn to constitute the blend of Al6Cu5Zn alloy are shown in Fig. 2. Regular shape and rough surface of Al powders are observed. This is commonly expected when milled powders are produced. Cu powders show irregular shapes, but lower rough surface than Al powders. This seems to be intimately associated with higher Cu ductility than Al. Morphology surfaces of the Al20Zn particles are similar to Al powders. However, the powder particles depict some deformation lines, which are characteristics remained from the milling adopted. A typical SEM image of the mixture of the three powers is shown in Fig. 2. Similar powder sizes are clearly evidenced (i.e. size ratio $1: 1$, independently of the considered powder nature). Cu powder particles are easily identified since their particles are brighter than other ones due to SEM technique used (secondary electron technique) and higher molecular weight.

Simultaneous analysis of the microstructure with the stress-strain engineering test (supplementary material) suggests the reduction of UTS $(68 \pm 10 \mathrm{MPa})$ when particle size is increased. It is reported by Rudianto et al. [10] that the size particles have critical roles up on the UTS results, since powder characteristics strongly affect the sinterability of the alloys. It is recognized that the larger particles 
difficult to rearrange of the powders and high porous is remained. This induces to high pore-solid interfacial area, and consequently, the free energy of the system is also increased [24].

The UTS value of $117 \pm 5 \mathrm{MPa}$ was obtained using particle sizes with a larger distribution range, with the particle size lower than $150 \mu \mathrm{m}$. According to Özay, Gencer and Gökçe [6], the irregular sizes of powders facilitate the rearrangement between particles, and consequently, the porosity after sintering is decreased. It is worth noting that the selection of a determined powder size range is the strict control of the distribution curve. This constitutes a drawback and the processing time is increased. Consequently, the final manufacturing cost is also enlarged.

It has also been reported that the accommodation inside die and dislocation of powders depend on the morphology and size particles [25]. From the experimental observations, the granulometry between 75$106 \mu \mathrm{m}$ has shown similar values of the powder sizes (117 MPa). Lumley and Schaffer [26] have obtained the best UTS using the same particle size range $(75-106 \mu \mathrm{m})$ when the Al-4Cu alloy was investigated.

\subsection{Microstructural and mechanical properties}

Since the highest UTS result is that of the range of the size particles 200 to 140 mesh $(75-106 \mu \mathrm{m})$, all other subsequent heat treatments are adopted using this size particle. The sintering temperatures at 585 , 600 and $615^{\circ} \mathrm{C}$ are carried out during $0.5 \mathrm{~h}$. Typical XRD patterns are shown in Fig. 3. Based on the experimented sintering temperatures, a thermodynamic condition to $\mathrm{Al}_{2} \mathrm{Cu}$ intermetallic is expected, as previously reported [22,23]. In fact, this is confirmed when the reflection peaks corresponding with Bragg planes (110), (200), (211) (220) (112) and (310) at angles $\sim 21^{\circ}, 30^{\circ}, 38^{\circ}, 42^{\circ}, 43^{\circ}$ and $\sim 47^{\circ}$ are characterized (JCPDS file number \# 01-1180). At angles $\sim 38^{\circ}, 44^{\circ}, 64^{\circ}, 78^{\circ}$ and $\sim 83^{\circ}$ corresponding with crystallographic planes (111), (200), (220), (311) and (222) indicating peaks associated with Al (JCPDS $\# 00-001-1180)$, as also previously reported $[18,22,23]$. Since powders of as-cast Al20Zn alloy are also used to constitute the AICuZn samples, at angle of about $41.5^{\circ}$, an overlapped peak seems to be correlated with $\mathrm{Zn}$-based solid solution. This phase is designated as $\eta-\sigma 0 \lambda_{1} \delta$ solution, $\mathrm{Zn}$-based $\mathrm{P}_{3} / \mathrm{mmc}$ (space group $\mathrm{n}^{\circ} 194$ with reference code 98-024-7160), as also reported by Gogola et al. [27]. At $\sim 48^{\circ}$ another overlapped peaks can be associated with another plane (202) corresponding with $\mathrm{Al}_{2} \mathrm{Cu}$.

It is clarified that the densification values depend of both the sintering times and temperatures, as depicted in Fig. 4. At $585^{\circ} \mathrm{C}$ to $615^{\circ} \mathrm{C}$, in a general way, the densifications have increased with the increase of the sintering period. Considering $0.5 \mathrm{~h}$ and $1.5 \mathrm{~h}$ of the sintering times, a higher sintering temperature has provided an increase of the densification. However, at $615^{\circ} \mathrm{C}$, when a higher liquid portion is provided, a slight decreasing trend of the densification is observed. Besides, when the sintering time of $3 \mathrm{~h}$ is considered, the three examined samples have very similar densification levels, as depicted in Fig. 4. Similar effect was also previously reported when $\mathrm{Al} / \mathrm{Cu}$ composites are sintered [22]. It is also found that the porosity tends to decrease with the increase of the sintering temperature, as shown in Fig. 4. This is associated with liquid phase filling porous and migrating to remained vacancies among the 
interfaces of the compacted powders. Lee and Ahn [3] have reported that the densification increases with increasing the temperature. The energy to activate the diffusion mechanisms is also increased. Consequently, the coalescence between the particles is increased and the porosity decreased.

Typical SEM micrographs of the Al6Cu5Zn samples at three different sintering temperatures are shown in Fig. 5. It is evidenced the decreasing trend of voids with the increase of the sintering temperature. It is found that the lowest porosity level is that of the Al6Cu5Zn sample sintered at $615^{\circ} \mathrm{C}$ for $0.5 \mathrm{~h}$. Although it is not systematically investigated, these porous seem to be associated with the remained porosity when compacting powders stage. Besides, it is also possible that some particular voids or micro voids are remained from a possible Kirkendall's voids constituted, mainly when sintering at $585^{\circ} \mathrm{C}$ is carried out. It is remembered that at this temperature no liquid-assisted sintering is predominant. Özay, Gencer and Gökçe [6] have reported that the liquid phase occurring in process induces to accelerate the diffusion mechanism. Besides, a possible thin layer of oxide on Al particles can be ruptured and bonding bridges between the particles are provided.

The experimental results of the stress $v s$. strain of the Al6Cu5Zn samples at three distinct sintering temperatures are shown in Fig. 6. Also, three different sintering times are demonstrated, i.e. $0.5,1.5 \mathrm{~h}$ and $3 \mathrm{~h}$, respectively. At a first analysis, it can be evidenced that during the three sintering periods, the sintered samples at 600 and $615^{\circ} \mathrm{C}$ exhibit similar mechanical behavior. When sintering for $0.5 \mathrm{~h}$ is analyzed, the obtained UTS is of about $80 \mathrm{MPa}$, while at $1.5 \mathrm{~h}$ and $3 \mathrm{~h}$, UTS values are 100 and $110 \mathrm{MPa}$, respectively. Also, it is found that the increase of the sintering period, the UTS is increased, i.e. $25 \%$ from $0.5 \mathrm{~h}$ to $1.5 \mathrm{~h}$ and $10 \%$ from $1.5 \mathrm{~h}$ to $3 \mathrm{~h}$ ( 90 to $100 \mathrm{MPa}$ and from 100 to $110 \mathrm{MPa}$, respectively).

Additionally, the worst UTS values are those of the Al6Cu $5 \mathrm{Zn}$ samples sintered at $585^{\circ} \mathrm{C}$. This is correlated to the fact that no assisted liquid phase is provided, as occurring with other examined samples sintered at 600 and $615^{\circ} \mathrm{C}$. When the samples are sintered during 0.5 and $1.5 \mathrm{~h}$, similar UTS values are reached. On the other hand, when the sintering for $3 \mathrm{~h}$ is analyzed, the sintered sample at $585^{\circ} \mathrm{C}$ has a same order of UTS magnitude when compared with other two samples examined. These observations are intimately associated with selected sintering temperatures.

A Zn-Al phase diagram is shown in Fig.7(a). Based on the chemical composition of the Al20Zn powder, under equilibrium condition, at $585^{\circ} \mathrm{C}$, a low portion of liquid can be formed. Differently, when the Al6Cu5Zn samples are sintered at 600 and $615^{\circ} \mathrm{C}$, where higher quantity of liquid phase is surely formed.Also, when the sintering period is increased, the liquid portion can be more easily constituted and it penetrates inside voids and micro voids neighboring the powder particles. Also, a possible micro voids (eventually constituted by Kirkendall effect) can be filled by liquid phase (Fig.7(b)). It is also remarked that $\mathrm{Cu}$ particles are also distributed throughout the examined composite. Although $\mathrm{Cu}$ particle has a melting point $\left(\sim 1084{ }^{\circ} \mathrm{C}\right)$ substantially higher than the sintering temperatures adopted; their atomic diffusion is intense and sufficiently to migrate preferentially at Al grain boundaries, as schematically represented in Fig.7(c). This has also reported by other researches $[23,28]$ when sintering $\mathrm{Al} / \mathrm{Cu}$ 
composites are investigated. At this sintering temperature, it is recognized that the diffusion of $\mathrm{Cu}$ into $\mathrm{Al}$ is higher than $10^{-8} \mathrm{~cm}^{2} \cdot \mathrm{s}^{-1}[22,23]$. This promotes a thermodynamic condition to $\mathrm{Al}_{2} \mathrm{Cu}$ intermetallic phase be formed.

It is also remarked that when the Al20Zn powder particles are liquefied, after its complete solidification, a resulting as-cast microstructural dendritic array is constituted. With this, Cu particles are dissolved and the as-cast Al20Zn portion possibly reacts with $\mathrm{Cu}$ and $\mathrm{Zn}$ content is diluted into Al matrix up to its solubility limit. This is corroborated with those low detected $\mathrm{Zn}$ concentrations, when the EDX analyses are carried out. When the obtained XRD and EDX partners are compared, it can be induced that Zn constitutes a solid solution phase ( $\eta$ phase).

A typical micrograph of the Al6Cu5Zn sample sintered at $585^{\circ} \mathrm{C}$ during $3 \mathrm{~h}$ and their corresponding EDX analysis are shown in Fig. 8(a). It is evidenced that elemental $\mathrm{Cu}$ (white region) has no completely consumed, as observed in the EDX intensity peaks. The EDX peaks associated with $\mathrm{Cu}$ and $\mathrm{Al}$ are also indicating that $\mathrm{Al}_{2} \mathrm{Cu}$ intermetallic is formed (ratio of $~ 1: 2$ ), as detected in XRD plots previously demonstrated. These are neighboring both $\mathrm{Cu}$ particles and at regions possibly constituted by crystallography Al grains and at powder interfaces.

It has been demonstrated that the intermetallic phase formations significantly improve the mechanical properties [29-32]. The EDX peak corresponding with $\mathrm{Zn}$ concentration is also characterized, as expected. From the metallurgical point of view, under an equilibrium condition, $\mathrm{Zn}$ content with liquid $(\mathrm{L})$ and solid $\eta$-phase can attain of about $5 \mathrm{wt} . \%$. The observed $\mathrm{Zn}$ content is agreed with this condition, although in the experimentations, a non-equilibrium condition seems to be occurred. Additionally, it seems that $n$ phase (Zn-based) solid solution phase is formed, as previously reported by Gogola et al. [27] that also indicated in both EDX and XRD results. Fig. 8(b) shows the typical micrograph and EDX analysis of the Al6Cu5Zn sample sintered at $615^{\circ} \mathrm{C}$ during $3 \mathrm{~h}$. The increase of $\mathrm{Al}_{2} \mathrm{Cu}$ content is observed in samples treated at these conditions.

\subsection{Natural aging results}

A natural aging is a phenomenon spontaneous of a supersaturated solid solution formed during room temperature heat treatment. Due to high number of retained atoms in solid solution after a rapid cooling, the hardening of naturally aged alloys is attained, as reported by Zhao et al. [33]. This occurs due to the GP zones nucleate homogeneously in the matrix (as thin plates) are constituted. During the natural aging of Al alloys, all increase in hardness are related to the formation of GP zones, and at temperatures below $100^{\circ} \mathrm{C}$, any other phases are not formed.

Figure 8 shows the hardness variation with aging period of the Al6Cu5Zn alloy for 210 days. It is verified that during 10 initial days the hardness from $\sim 77$ to $\sim 85 \mathrm{HV}$ has increased. This is attributed to the formation of GP zones precursor to the metastable phase that occurs gap-controlled diffusion, as reported by Ogura et al. [34]. This mechanism is possible due to high retention of gaps, as resulted from water quenching. Considering aging period higher than 120 days, majority solute precipitation has 
occurred. A trend to stabilize hardness is observed, as shown in Fig. 9. Similar behavior is also observed when Buha, Lumley and Grosky [35] have investigated Al7050 alloy in distinct aging periods.

Binary Al-Cu alloys have relative stability of mechanical properties in few days. The $\mathrm{Zn}$ amount into Al-Cu alloy affects the stability at room temperature, and it also contributes to increase mechanical properties over the years $[36,37]$. The formation of $\mathrm{Al}_{4} \mathrm{Cu}_{3} \mathrm{Zn}$ phase is induces when $\mathrm{Zn}$ content is considered, when a peritectic reaction between liquid and $\mathrm{Al}-\mathrm{Cu}$ is prevalent. Such phase is formed between 500 and $600^{\circ} \mathrm{C}$ and the stability occurs $\sim 300^{\circ} \mathrm{C}\left[8,38\right.$ ]. Cardenas et al. [39] have demonstrated that the $\mathrm{Al}_{4} \mathrm{Cu}_{3} \mathrm{Zn}$ phase has a beneficial effect on hardness of the $\mathrm{Zn}$-Al-Cu alloys. It is remarked that $\mathrm{Al}_{4} \mathrm{Cu}_{3} \mathrm{Zn}$ phase is not identified in the experimental results of the XRD patterns. As aforementioned, a Zn-based solution is more probably constituted.

To predict the mechanical behavior, the mathematical model using a non-linear regression analysis is used and the hardness with aging time is determined, as described in Equation 1:

$$
\text { Hardness }(H V)=100.43-6.69^{-x} / 3.51-8.86^{-x} / 74.93-8.71^{-x} / 74.94
$$

From Equation 1, the HV saturation probably occurs at 500 days ( 100.42 HV). Although, a drop of hardness is attributed to over-aging occurring in Al-Cu based alloys, Equation \#1 is not able to predict this occurrence.

From the above obtained experimental results, it can be observed that the mechanical behavior of the Al6Cu5Zn alloy is similar to as-cast Al alloys. This suggests that the proposed alloy and the adopted liquid-assisted sintering are promise and ecological manufacturing process. This due to lower costs can be associated with low energy consumption, without melting point is reached.

\section{Conclusions}

This work is focused on the microstructural and mechanical properties characterizations of noncommercial Al6Cu5Zn alloy, which is manufactured by using liquid-assisted sintering. From the experimental results, the follow conclusion can be drawn:

1. A selective of the particle sizes has permitted that powders ranging between 200 and 140 mesh; the better UTS values are induced;

2. Considering this same particles size associated with a compaction pressure of $364 \mathrm{MPa}$, a densification level of about $85 \%$ is attained; and

3. From the distinct sintering temperatures and times, it is found that UTS of $125 \mathrm{MPa}$ is reached when sintering at $615^{\circ} \mathrm{C}$ during $3 \mathrm{~h}$ is considered. This value is similar to as-cast Al-Cu based alloys (without heat treatments). Additionally, it is also suggested that the hardness reaches of about $99 \mathrm{HV}$ after natural aging for 500 days. With these attained mechanical properties, it is induced that the Al and Cu elemental 
powders can be associated with Al-Zn powder to constitute an Al6Cu5Zn alloy with some advantages such as energy consumption and metal fumes commonly detected in foundry.

\section{Declarations}

\section{Conflicts of interest}

The authors declare no conflicts of interest regarding the publication of this paper.

\section{Acknowledgements}

The authors acknowledge the support by the CNPq (310010/2020-9), FAPESP (2013/12729-5, 2016/13352-0) and CAPES (Eder Lopes Ortiz master fellowship).

\section{References}

[1] B. Stojanovic, M. Bukvic, I. Epler, Application of aluminum and aluminum alloys in engineering, Appl. Eng. Lett. 3 (2018) 52-62. https://doi.org/10.18485/aeletters.2018.3.2.2

[2] Y. Zhu, K. Sun, G.S. Frankel, Intermetallic phases in aluminum alloys and their roles in localized corrosion, J. Electrochem. Soc. 165 (2018) C807-C820. https://doi.org/10.1149/2.093181jes

[3] S.H. Lee, B. Ahn. Effect of compaction pressure and sintering temperature on the liquid phase sintering behavior of Al-Cu-Zn alloy, Arch. Metall. Mater. 60 (2015) 158-162. https://doi.org/10.1515/amm-20150158

[4] V. Chak, H. Chattopadhyay, T.L. Dora, A review on fabrication methods, reinforcements and mechanical properties of aluminum matrix composites, J. Manuf. Process. 56 (2020) 1059-1074. https://doi.org/10.1016/j.jmapro.2020.05.042

[5] R.S. Bonatti, R.R. Siqueira; G.S. Padilha, A.D. Bortolozo, W.R. Osório, Distinct $\mathrm{Al}_{\mathrm{p}} / \mathrm{Si}_{\mathrm{p}}$ composites affecting its densification and mechanical behavior, J. Alloy. Compd. 757 (2018) 434-447. https://doi.org/10.1016/j.jallcom.2018.05.055

[6] Ç. Özay, E.B. Gencer, G. Ökçe, Microstructural properties of sintered Al-Cu-Mg-Sn alloys. J. Therm Anal. Calorim. 134 (2018) 23-33. https://doi.org/10.1007/s10973-018-7171-5

[7] H.T. Naeem, K.S. Mohammed, K.R. Ahmad, The role of cobalt and nickel intermetallic phases on the mechanical properties and microstructure evolution of Al-Zn-Mg-Cu alloys, Mater. Res. 17 (2014) 16631676. https://doi.org/10.1590/1516-1439.312114

[8] S-M. Liang, R. Schmid-Fetzer, Thermodynamic assessment of the Al-Cu-Zn system, part II: Al-Cu binary system, Calphad: Comput. Coupling Ph. Diagr. Thermochem. 51 (2015) 252-260. 
[9] W.T. Hou, J.T. Shi, L.G. Hou, J.S. Zhang, An improved thermo-mechanical treatment of high-strength $\mathrm{Al}-\mathrm{Zn}-\mathrm{Mg}-\mathrm{Cu}$ alloy for effective grain refinement and ductility modification, J. Mater. Process. Technol. 239 (2017) 303-214.

https://doi.org/10.1016/j.jmatprotec.2016.08.027

[10] H. Rudianto, G.J. Jang, S.S. Yang, Y.J. Kim, I. Dlouhy, Evaluation of sintering behavior of premix Al-ZnMg-Cu alloy powder, Adv. Mater. Sci. Eng. 15 (2015) 1-8. https://doi.org/10.1155/2015/987687

[11] J.E. Hatch, Aluminum: Properties and Physical Metallurgy. ASM International, Metals Park, EUA, 1990.

[12] J.W. Martin, Precipitation Hardening, second ed., Butterworth-Heinemann, Oxford, 1998.

[13] J. G. Byrne, M.E. Fine, A. Kelly, Precipitate hardening in an aluminium-copper alloy, The Philos. Mag.: A Journal of Theoretical Experimental and Applied Physics, 6 (1961) 1119-1145.

https://doi.org/10.1080/14786436108239674

[14] W.J. Poole, J.D. Embury, D.J. Lloyd, Work hardening in aluminium alloys, in: R. Lumley (Ed.), Fundamentals of aluminium metallurgy, Woodhead Publishing (2011), pp. 305-344.

[15] J. Ngugi, G.O. Rading, B.O Odera, B. Ngobe, R. Forbes, L.A. Cornish, Partial isothermal sections of the Cu-rich corner of the Al-Cu-Zn system at 200 and $240{ }^{\circ} \mathrm{C}$, J. Phase Equilib. Diffus. 40 (2019) 588-599. https://doi.org/10.1007/s11669-019-00746-8

[16] R. S. Rana, R. Purohit, S. Das, Reviews on the influences of alloying elements on the microstructure and mechanical properties of aluminum alloys and aluminum alloy composites, Int. J. Sci. Res. 2 (2012) $1-7$.

[17] S. Pournaderi, F. Akhlaghi, Wear behaviour of Al6061-Al203 composites produced by in-situ powder metallurgy (IPM), Powder Technol. 313 (2017) 184-190. https://doi.org/10.1016/j.powtec.2017.03.019

[18] A.L.P. Elias, M.S. Koizumi, E.L. Ortiz, J.F.Q. Rodrigues, A.D. Bortolozo, W.R. Osório, G. S. Padilha, Corrosion behavior of an Al-Si casting and a sintered $\mathrm{Al} / \mathrm{Si}$ composite immersed into biodiesel and blends, Fuel Process. Technol. 202 (2020), 106360. https://doi.org/10.1016/j.fuproc.2020.106360

[19] A. Mostafaei, P.R. De Vecchis, V. Nettleship, M. Chmielus, Effect of powder size distribution on densification and microstructural evolution of binder-jet 3D-printed alloy 625, Mater. Des. 162 (2019) 375383. https://doi.org/10.1016/j.matdes.2018.11.051

[20] H.R. Hafizpour, A. Simchi, Investigation on compressibility of Al-SiC composite powders, Powder Metall. 51(2008) 217-223. https://doi.org/10.1179/174329007X22250 
[21] D. Bouvard, Densification behaviour of mixtures of hard and soft powders under pressure, Powder Technol. 111(2000) 231-239. https://doi.org/10.1016/S0032-5910(99)00293-4

[22] Y.A. Meyer, R.S. Bonatti, D. Costa, A.D. Bortolozo, W.R. Osório, Compaction pressure and Si content effects on compressive strengths of Al/Si/Cu alloy composites, Mater. Sci. Eng. A. 770 (2020), 1385747. https://doi.org/10.1016/j.msea.2019.138547

[23] L.M. Satizabal, H.F.N. Caurin, Y.A. Meyer, G.P. Padilha, A.D. Bortolozo, W.R. Osório. Distinct heat treatments and powder size ratios affecting mechanical behavior of $\mathrm{Al} / \mathrm{Si} / \mathrm{Cu}$ composites, J. Compos. Mater. 2021, in press.

[24] K.P. Su, X.X. Chen, O. Wang, D.X. Huo, Z.W. Liu, Effect of milling on the structure and magnetic properties in $\mathrm{Mn}_{54} \mathrm{Al}_{46}$ flakes prepared by surfactant-assisted ball milling, Mater. Charact. 114 (2016) 263266. https://doi.org/10.1016/j.matchar.2016.03.011

[25] P.A. Pulido-Suárez, K.S. Uñate-Gonzälez, J.G. Tirado-González, A. Esquerra-Arce, J. Esquerra-Arce, The evolution of the microstructure and properties of ageable Al-Si-Zn-Mg alloy during the recycling of milling chips through powder metallurgy, J. Mater. Res. Technol. 9 (2020) 11769-1777.

https://doi.org/10.1016/j.jmrt.2020.08.045 [26] R.N. Lumley, G.B. Schaffer, The effect of additive particle size on the mechanical properties of sintered aluminium-copper alloys, Scr. Mater. 39 (1998), 1089-1094. https://doi.org/10.1016/S1359-6462(98)00278-4

[27] P. Gogola, Z. Gabalcová, H. Suchánek, M. Babinec, M. Bonek, M. Kusý, Quantitative X-ray diffraction analysis of Zn-Al based alloys, Arch. Metall. Mater. 65 (2020) 959-966. https://doi.org/10.24425/amm.2020.132844

[28] B. Ogel, R. Gurbuz, Microstructural characterization and tensile properties of hot pressed Al-SiC composites prepared from pure Al and Cu powders, Mater. Sci. Eng. A. 301 (2001) 213-220. https://doi.org/10.1016/S0921-5093(00)01656-7

[29] S.O. Adeosun,; S.A. Balogun, L.O. Osoba, W.A. Ayoola, A.M. Oladoye, Effect of Cu and Zn addition on the mechanical properties of structural aluminum alloy, Int. J. Mod. Manuf. Technol. 3(2011), 103-110.

[30] S. Engin, U. Büyük, N. Maraşli, The effects of microstructure and growth rate on microhardness, tensile strenght, and electrical resistivity for directionally solidified Al-Ni-Fe alloys, J. Alloy. Compd. 660 (2016) 23-31. https://doi.org/10.1016/j.jallcom.2015.11.080

[31] P.R. Matli, U. Fareeha, R.A. Shakoor, A.M.A. Mohamed, A comparative study of structural and mechanical properties of Al-Cu composites prepared by vacuum and microwave sintering techniques, $\mathrm{J}$. Mater. Res. Technol. 7 (2018), 165-172. https://doi.org/10.1016/j.jmrt.2017.10.003

[32] W.S. Ebhota, T-C. Jen, Formation and their effect on mechanical properties of Al-Si-X alloys. In: Mahmood Aliofkhazraei (Ed.). Intermetallic Compounds - Formation and Applications, 2018. 
[33] J. Zhao, Z. Liu, S. Bai, D. Zeng, L. Luo, L. Wang, Effects of natural aging on the formation and strengthening effect of G.P. zones in a retrogression and re-aged Al-Zn-Mg-Cu alloy, J. Alloy. Compd. 829 (2020), 154469, https://doi.org/10.1016/j.jallcom.2020.154469

[34] T. Ogura, S. Hirosawa, A. Cerezo, T. Sato, Atom probe tomography of nanoscale microstructures within precipitate free zones in Al-Zn-Mg(-Ag) alloys, Acta Mater. 58 (2010), 5714-5723. https://doi.org/10.1016/j.actamat.2010.06.046

[35] J. Buha, R.N. Lumley, A.G. Crosky, Secondary ageing in an aluminum alloy 7050, Mater. Sci. Eng. A. 25 (2008) 1-10. https://doi.org/10.1016/j.msea.2008.02.039

[36] H. Chen, X. Xin, D.Y. Dong; Y.P. Ren, S.M. Hao, Study on the stability of the T' phase in the Al-Zn-Cu ternary system, Acta Metall. Sin. 17(2004), 269-273.

[37] A. Abolfazl, A.K. Taheri, K.K. Taheri, K.K. Recent advances in ageing of 7xxx series aluminum alloys: A physical metallurgy perspective, J. Alloy. Compd. 781 (2019), 945-983.

https://doi.org/10.1016/j.jallcom.2018.11.286

[38] O. Zobac, A. Kroupa, K.W. Richter, Experimental study of the Al-Cu-Zn ternary phase diagram, J. Mater Sci. 55 (2020), 10796-10810. https://doi.org/10.1007/s10853-020-04686-4

[39] J.D. Villegas-Cardenas, V.M. Lopez-Hirata, M.L. Saucedo-Muñoz, J.L. Gonzalez-Velazquez, E.O. AvilaDavila, Effect of phase transformations on hardness in Zn-Al-Cu alloys, in: S.J. Ikhmayies, B. Li, J.S. Carpenter, J-Y. Hwang, S.N. Monteiro, J. Li, D. Firrao, M. Zhang, Z. Peng, J.P. Escobedo-Diaz, C. Bai (Eds.), Characterization of Minerals, Metals, and Materials, John Wiley \& Sons, 2016, pp. 515-521. https://doi.org/10/1007/978-3-319-48210-1_64

\section{Figures}



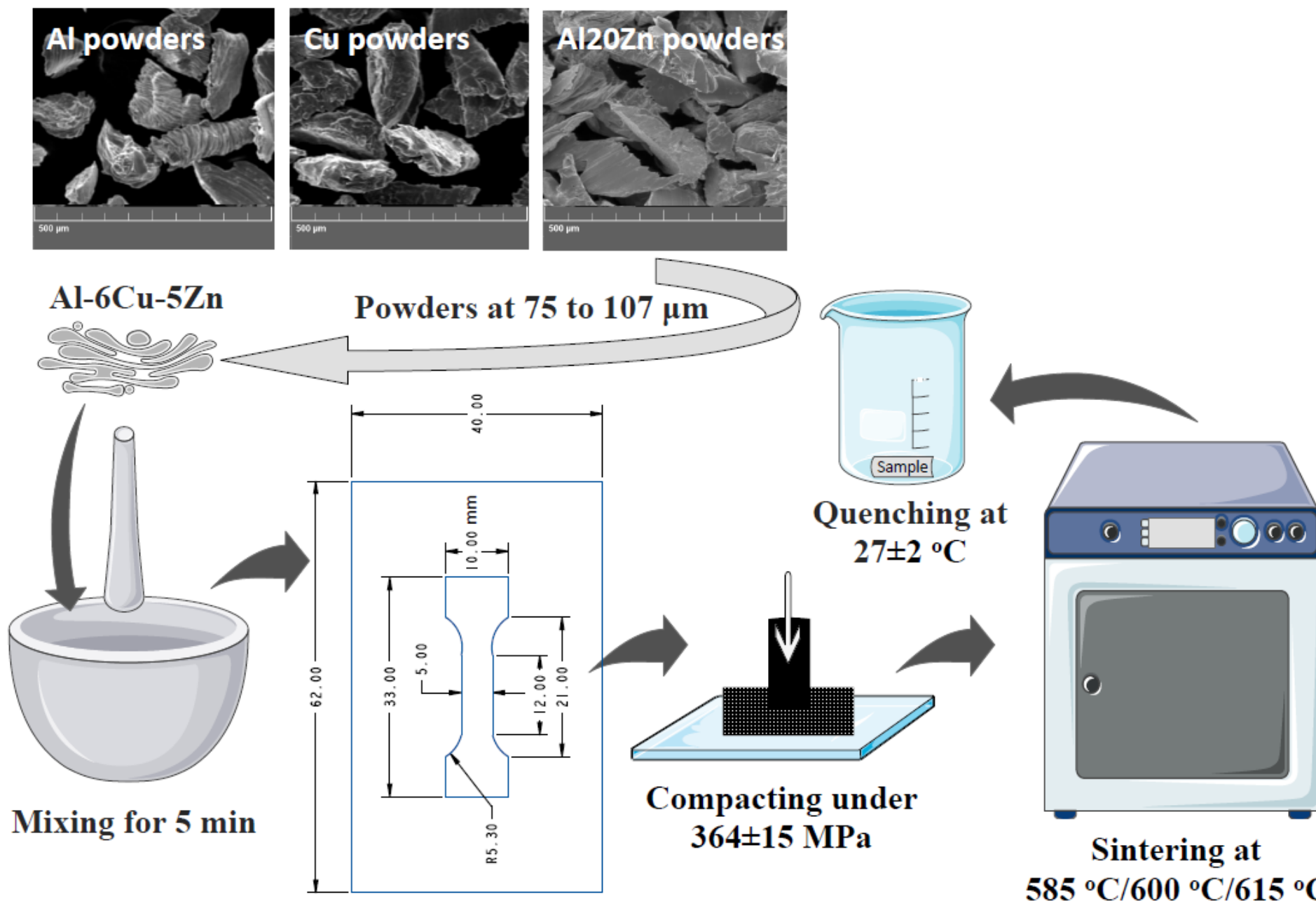

Figure 1

Schematic representation of the alloy manufactured by powder metallurgy. 

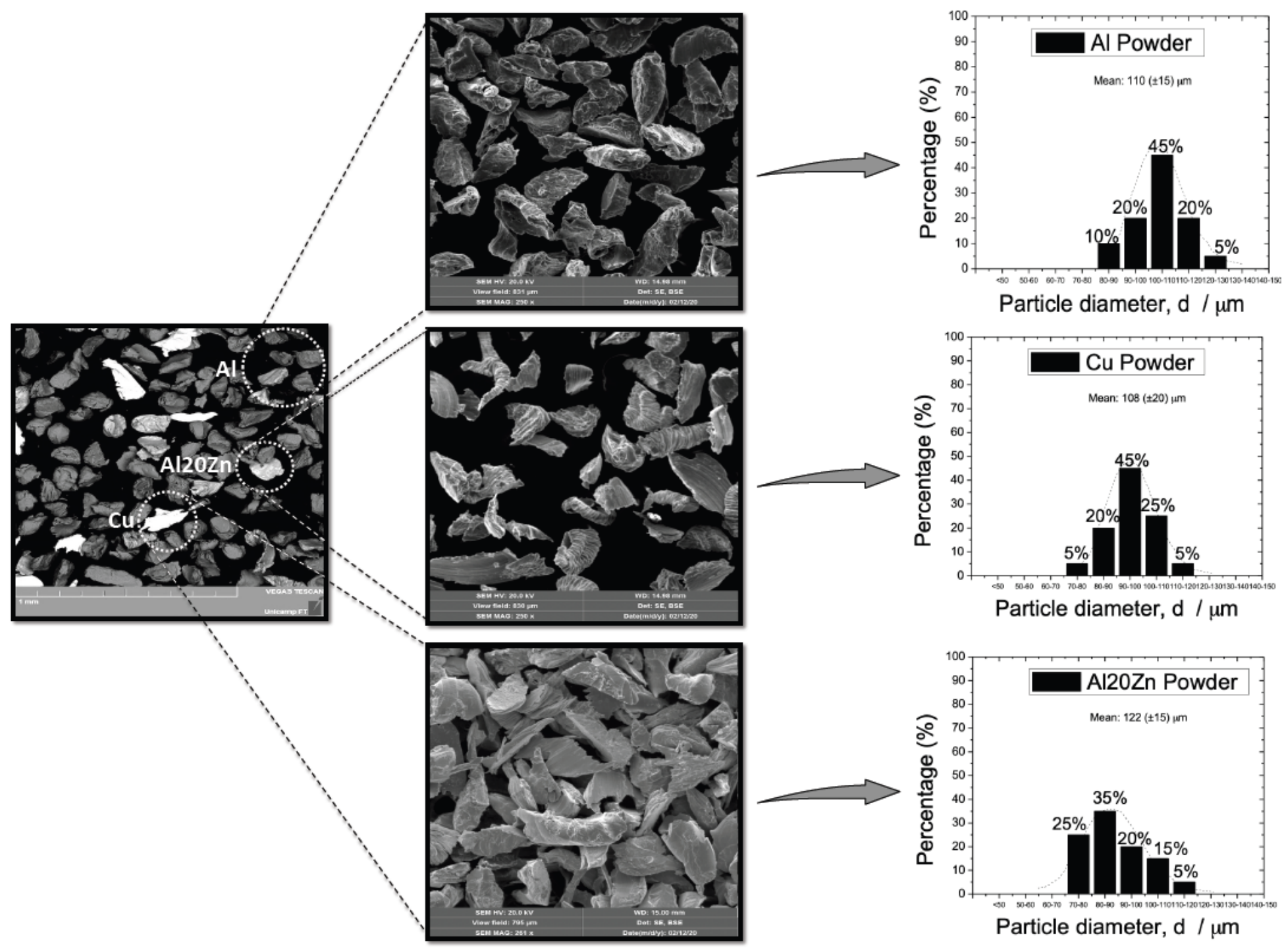

Particle diameter, $\mathrm{d} / \mu \mathrm{m}$

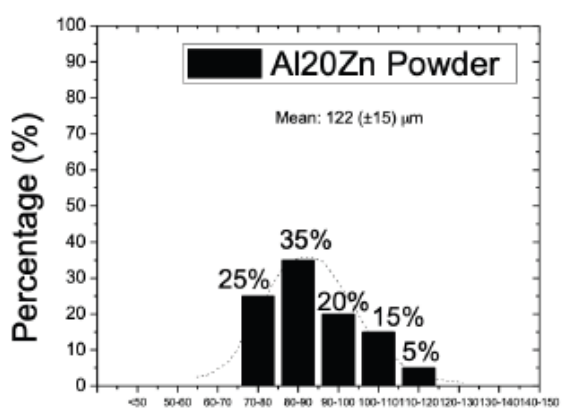

Particle diameter, $\mathrm{d} / \mu \mathrm{m}$

Figure 2

Typical SEM images of the morphology of $\mathrm{Al}, \mathrm{Cu}, \mathrm{Al} 20 \mathrm{Zn}$ powders and the blend to constitute the Al6Cu5Zn alloy. Magnification of $250 \mathrm{x}$. 


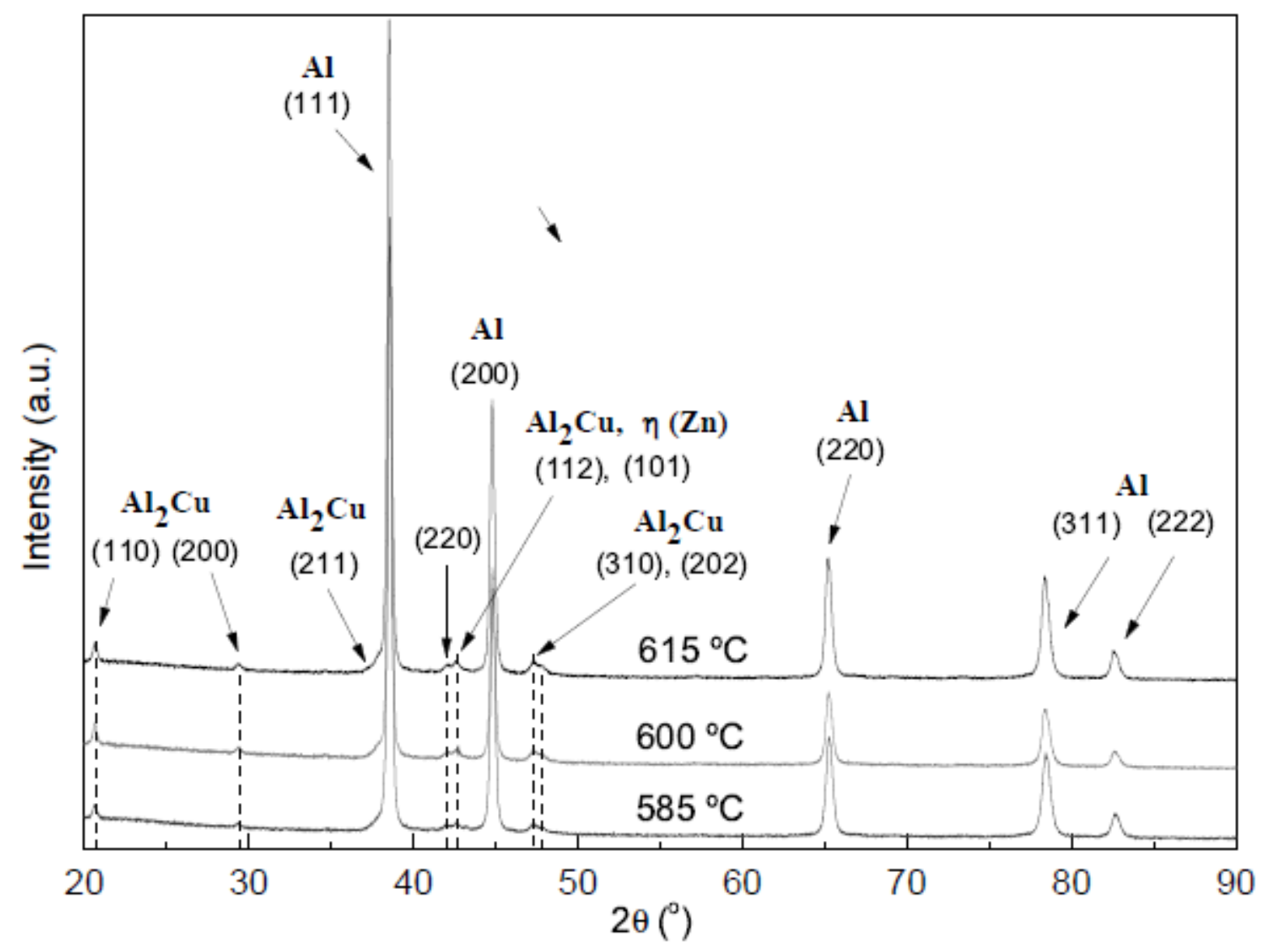

Figure 3

XRD patterns of the Al6Cu5Zn alloy at $0.5 \mathrm{~h}$. 


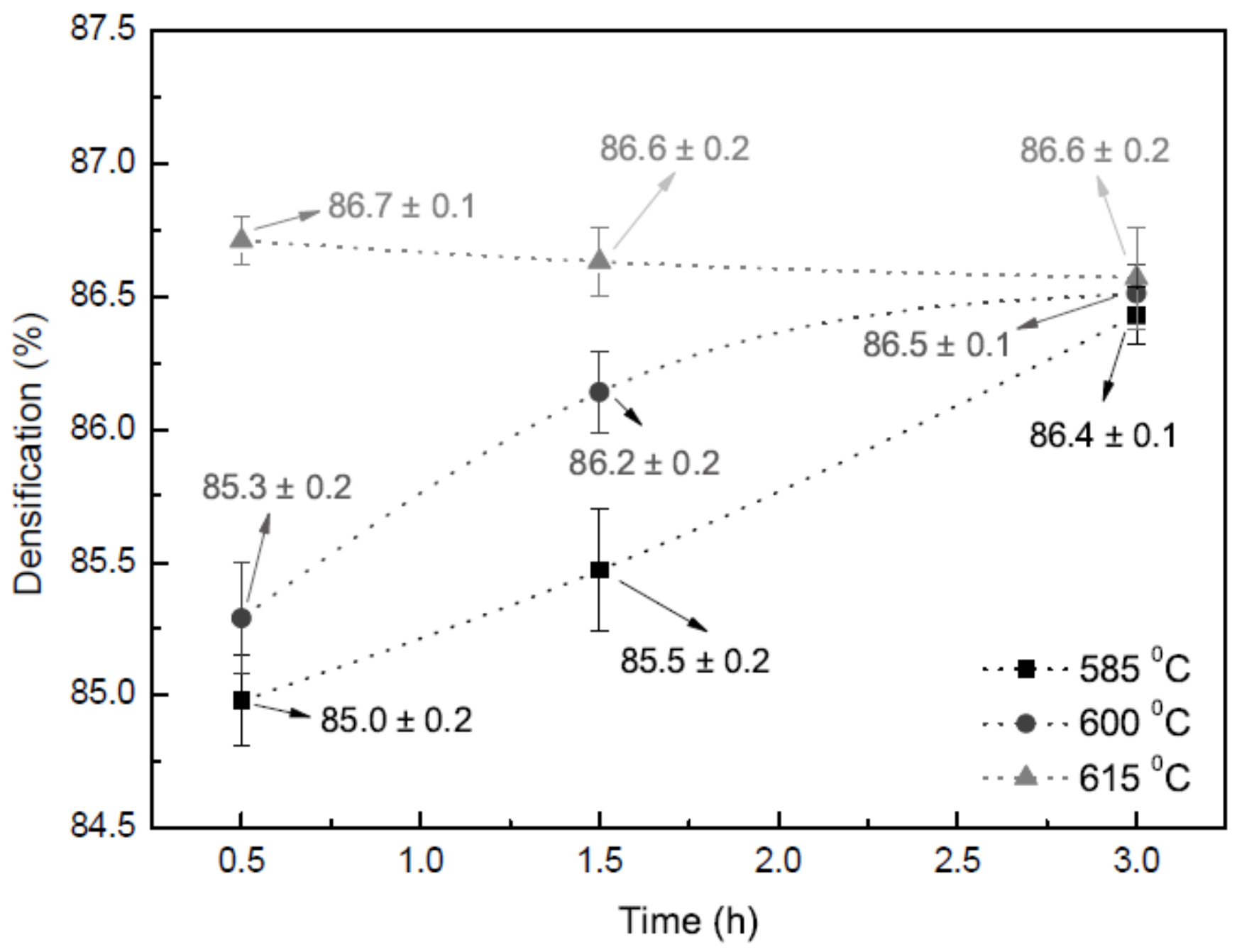

Figure 4

Densification for different temperature and sintered times obtained from the Archimedes method. 

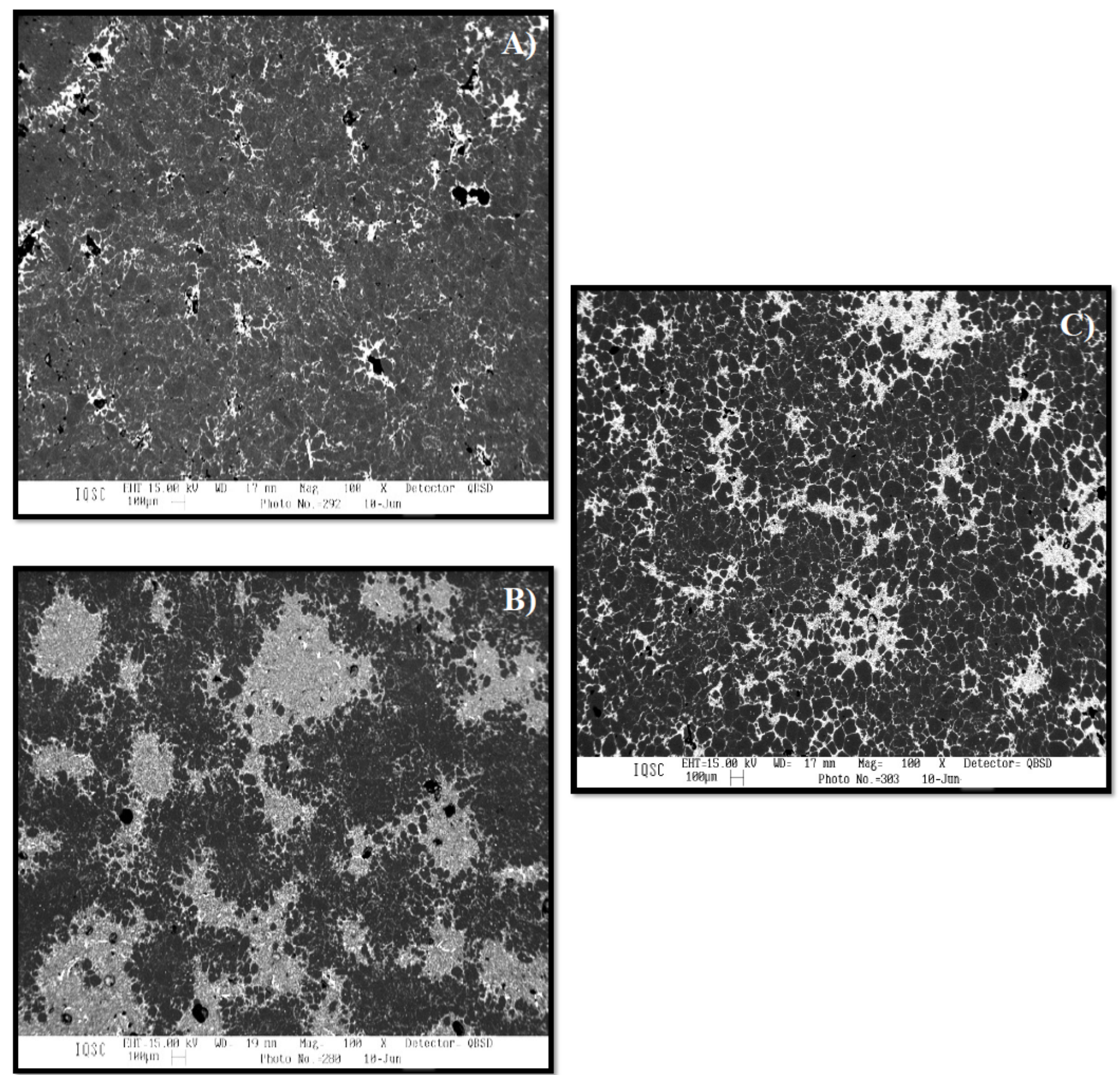

Figure 5

Tipical SEM micrographs of the Al6Cu5Zn samples sintered during $0.5 \mathrm{~h}$ at: A) $585^{\circ} \mathrm{C}$; B) $600^{\circ} \mathrm{C}$; and C) $615^{\circ} \mathrm{C}$. 

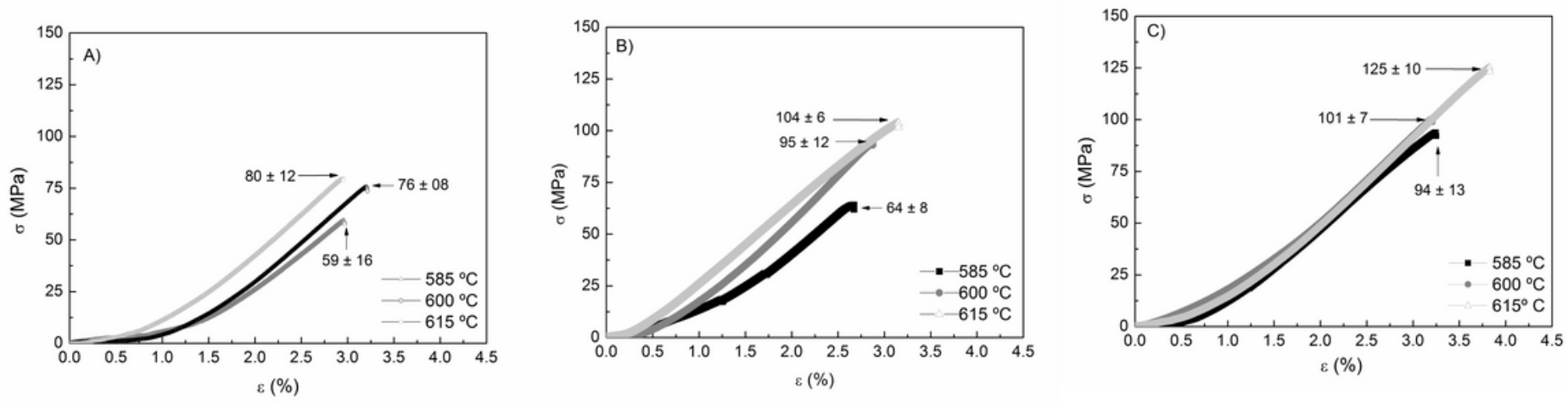

Figure 6

Experimental results of engineering stress-strain values as function of the both sintering time and temperature: A) $0.5 \mathrm{~h}$; B) $1.5 \mathrm{~h}$ and C) $3 \mathrm{~h}$. 

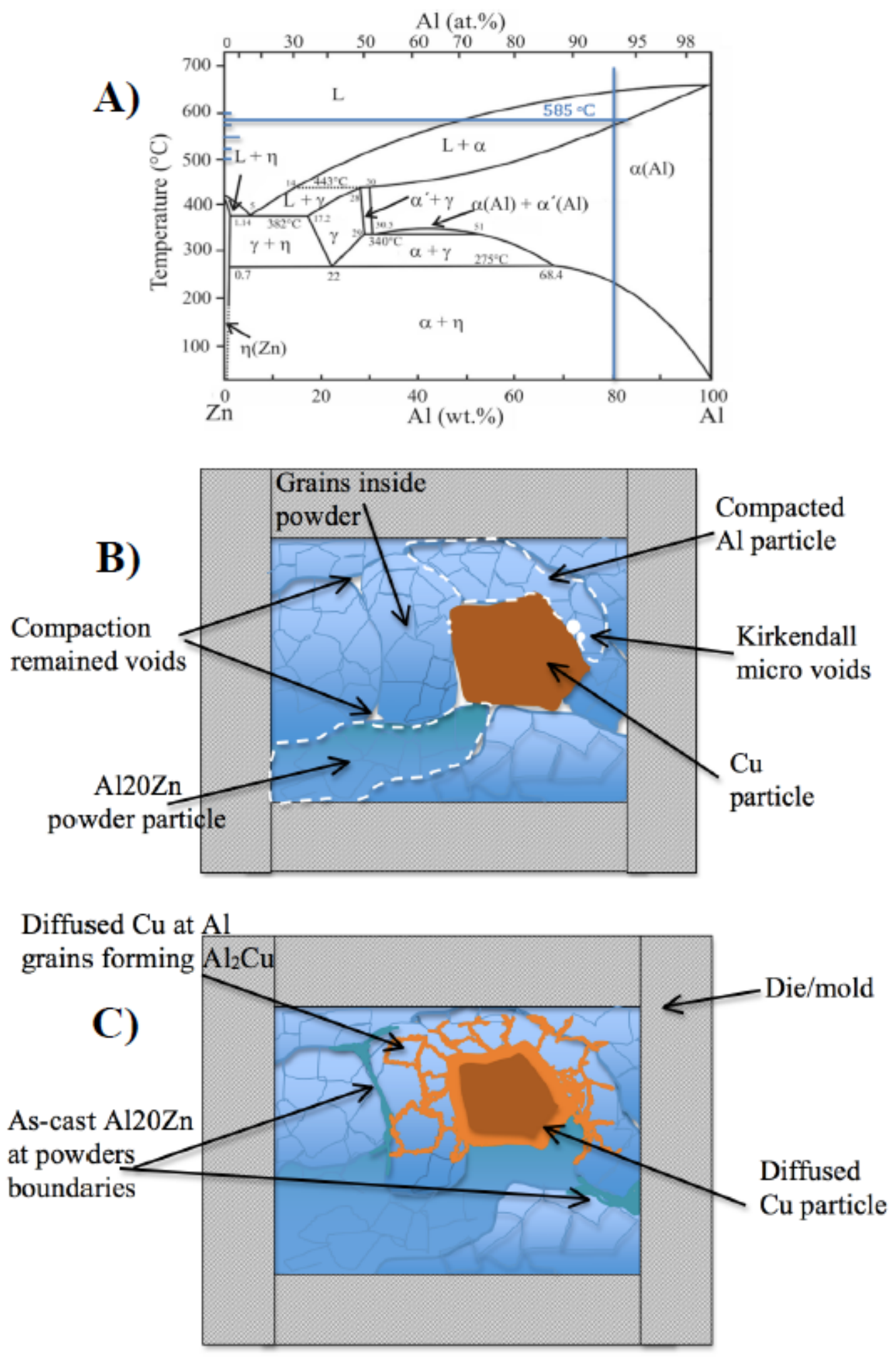

Figure 7

A) Binary Zn-Al phase diagram, B) schematic representation of compacted and sintered powders at 585 ${ }^{\circ} \mathrm{C}$ and; $\mathrm{C}$ ) evidencing difussed $\mathrm{Cu}$ particles forming $\mathrm{Al} 2 \mathrm{Cu}$ intermetallic and acomodattion of liquid phase (as-cast) boundaring powder particles. 

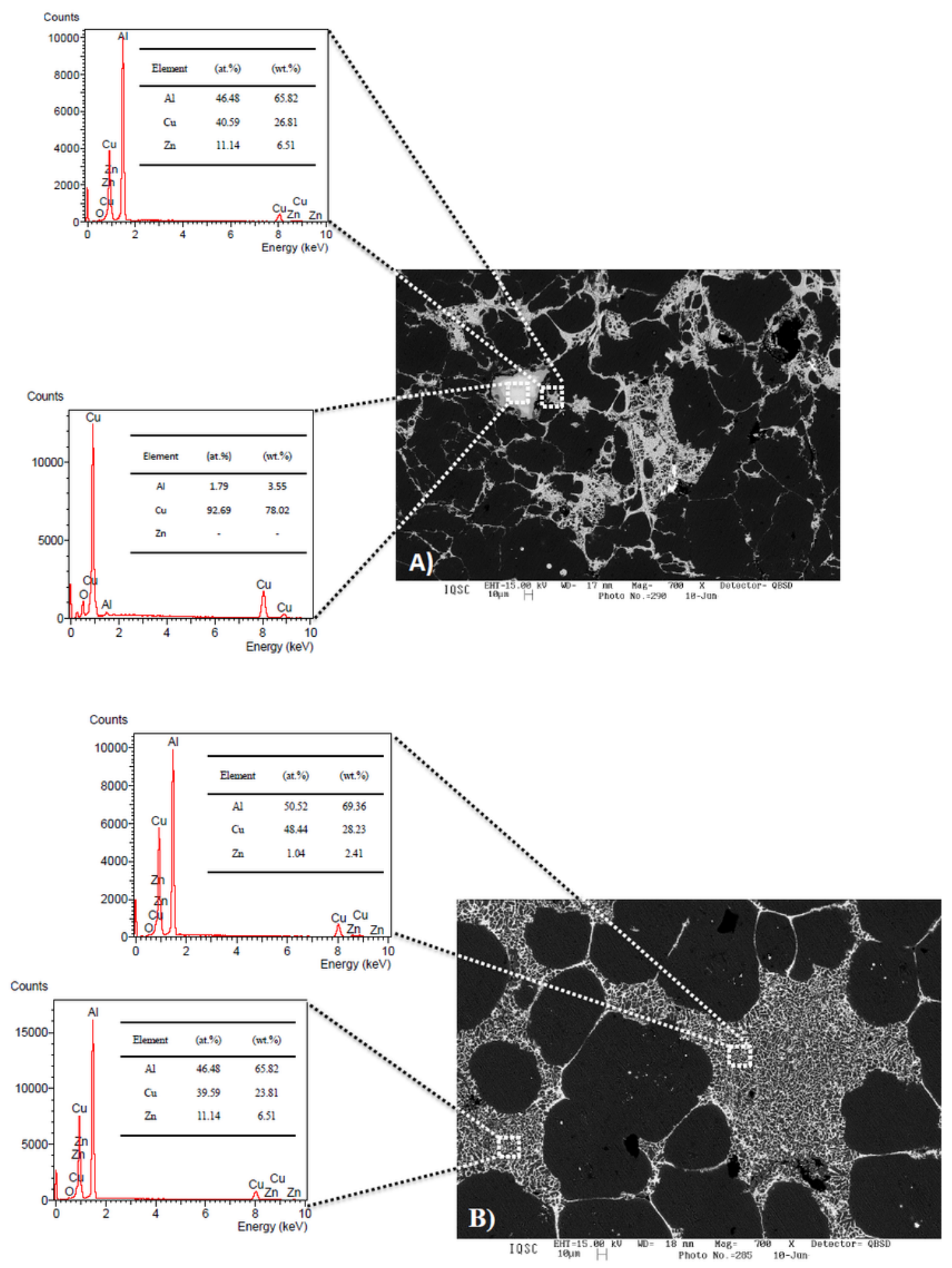

Figure 8

Typical SEM and EDX results of the Al6Cu5Zn alloy at: A) $585^{\circ} \mathrm{C}$ for $3 \mathrm{~h}$; and B) $600^{\circ} \mathrm{C}$ for $3 \mathrm{~h}$. 


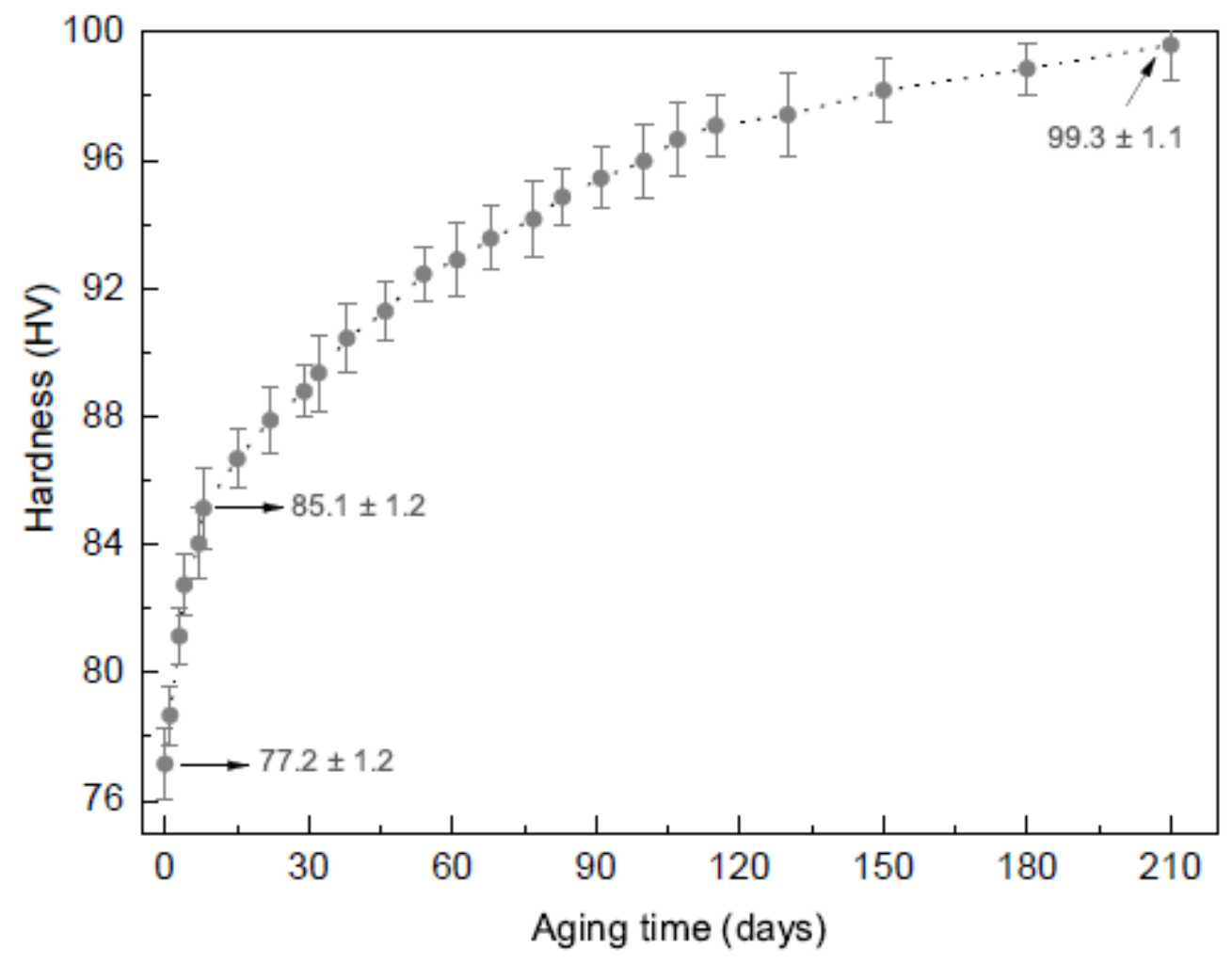

Figure 9

Variation of hardness of the Al6Cu5Zn as function of natural aging period.

\section{Supplementary Files}

This is a list of supplementary files associated with this preprint. Click to download.

- Supplmat.tif 